\title{
Península, península; el Yucatán del siglo XIX en la memoria del novelista contemporáneo
}

\author{
Tatiana SuÁrez Turriza \\ Centro Peninsular en Humanidades y Ciencias Sociales \\ Universidad Nacional Autónoma de México \\ tatianne679@hotmail.com
}

\begin{abstract}
Resumen: Este ensayo analiza el diálogo que la novela Península, península (2008) de Hernán Lara Zavala entabla con la tradición literaria decimonónica, en particular, con la obra de Justo Sierra O'Reilly. Se estudia la "reabsorción” de la tradición literaria e histórica del siglo XIx "peninsular mexicano" que la novela tematiza. Se identifican algunos de los intertextos e intratextos de la novela, los cuales evidencian el trabajo de archivo que hay detrás de la obra. Para el análisis se tiene en cuenta el concepto de "pastiche", como la forma en que se estructura esa intertextualidad.
\end{abstract}

Aвstract: This paper analyzes the dialogue that the novel Peninsula, peninsula (2008) by Hernán Lara Zavala engages with nineteenth-century literary tradition, in particular with the work of Justo Sierra O'Reilly. It studies the "absorption" of the literary and historical tradition of the nineteenth century in the mexican peninsula, that the novel thematizes. It identifies some of the intertexts of the novel, which show the archival work behind it. The analysis takes the concept of "pastiche" into consideration, as the way this intertextuality is structured.

Palabras Clave: novela histórica, literatura decimonónica, memoria, intertextualidad, microhistoria.

KEYwORDS: historical novel, nineteenth century literature, memory, intertextuality, microhistory.

Peninsula, peninsula de Hernán Lara Zavala se suma al acervo literario de novelas históricas de México. En los albores del México independiente, la novela histórica representó una vía de exploración y definición del "ser nacional". A casi dos siglos de distancia la novela histórica ocupa un lugar central en la producción literaria contemporánea, porque nuestra condición cultural está marcada por la necesidad de reflexionar siempre sobre nuestro pasado para poder entender y definir nuestro presente. 
Si bien los autores de novelas históricas del siglo XIX, fuertemente comprometidos con un proyecto social y político, se proponían contribuir a la definición de una historia nacional, la nueva novela histórica parece volcarse precisamente sobre el discurso de esa historia ya fijado, sobre todo desde la perspectiva de escritores e historiadores decimonónicos, para ampliarla, cuestionarla o desplegar otros posibles sentidos. Gerardo Bobadilla hace notar un rasgo definitorio de la novela histórica mexicana del siglo XIX que marca esa distancia determinante con relación al género en el contexto contemporáneo: "La novela histórica en México se enfrenta, pues, a una Historia nacional que se está haciendo - como constructo racional—y que, según las etapas de su definición, elabora nuevas imágenes históricas" (25).

Peninsula, peninsula trae a la ficción un suceso de trascendencia en la historia de Yucatán: la guerra de castas, que, sin embargo, representa un vacío, un periodo casi ignorado, en el discurso histórico nacional. La perspectiva centralista del quehacer histórico ha desatendido la historia particular de las regiones. Esta novela no solo entabla un diálogo con la historia, al ampliar, llenar o dar otro sentido mediante la ficción a un pasaje de la historia "peninsular", también es una obra que dialoga con su propia tradición literaria, es decir, con la de la novela histórica mexicana. Una serie de reflexiones metatextuales, en voz de un autor implícito, enmarca una ficción de raigambre histórica que se urde frente al lector y de la que, deliberadamente, se expone el artificio. ${ }^{1}$

En este trabajo me interesa hacer evidente el diálogo que la novela plantea con la tradición literaria del género "novela histórica", sobre todo la del siglo XIx mexicano. Mediante el análisis del recurso metaficcional antes aludido, pretendo exponer, en el primer apartado, la intención de llevar a cabo una novela que en su forma y estilo muestre

\footnotetext{
${ }^{1}$ Seymour Menton, en su conocido estudio sobre la "nueva novela histórica", argumenta que una de las características que distinguen al género en su "versión" contemporánea es, precisamente, la metaficción o los comentarios del narrador sobre el proceso de creación. Expone otros rasgos que son también fácilmente identificables en Península, península, como "la subordinación de la reproducción mimética de cierto periodo histórico a la presentación de algunas ideas filosóficas [...] [tales como] la imposibilidad de conocer la verdad histórica o realidad; el carácter cíclico de la historia"; la ficcionalización de personajes históricos, a diferencia de la fórmula de Walter Scott —aprobada por Lukács — de protagonistas ficticios; la intertextualidad; "los conceptos bajtinianos de lo dialógico, lo carnavalesco, la parodia y la heteroglosia” (42.)
} 
también esa reformulación del pasado literario, de la tradición, en el presente. Podría decirse que Península, peninsula tematiza la reabsorción del pasado en el presente, en específico de la memoria histórica y literaria decimonónica peninsular. Rasgo que recuerda el concepto de "lugar de memoria", explorado por François Hartog, quien lo toma de Pierre Nora, que postula que el modo de ser del pasado es el del surgimiento en el presente, pero bajo el control del historiador (Hartog: 155). Es decir, en forma y en estilo esta novela muestra que la única manera de ser del pasado, simbolizado por la novela perdida de Turrisa que el autor "re-escribe", es el "surgimiento en el presente".

\section{Del Siglo XIX Al SIGLO XXI; CÓMO NOVELAR UNA "MISMA" HISTORIA}

En la novela, la mirada "crítica" al pasado contempla dos ámbitos: la historia social y política de Yucatán en el siglo xIX, y la historia o tradición literaria del género "novela histórica". La mayoría de las reflexiones del autor implícito, el que escribe con una "pluma Parker de tinta sepia" o en su computadora Macintosh, en torno a su proceso creativo, aparecen, por lo general, al inicio de aquellos capítulos en los que se dispone a contar y escribir bajo el "disfraz" de José Turrisa, novelista decimonónico. En ellas, el autor deja en claro que la revisión del pasado que la creación de su obra implica, tiene como propósito el análisis del presente: "Quienes nos acercamos a la historia para ubicar novelas en un tiempo pasado no hacemos sino aprovechar otra época para reflexionar sobre el presente" (Lara 2008: 79). Por ese motivo, a lo largo del relato, la voz del narrador-autor del presente suele intervenir para enjuiciar e incluso confrontar con su tiempo los hechos del pasado rememorado desde la supuesta perspectiva del novelista decimonónico.

Aunque el narrador contemporáneo nunca otorga del todo la voz al novelista-narrador del pasado, el relato suele ostentar un estilo y tono decimonónico. Por ejemplo, la apelación a "las queridas lectoras" con la que infiltra, en ciertos momentos, su juicio sobre el presente a partir de una situación del pasado es muy de tono decimonónico: "Y las relaciones de mujeres blancas con indios eran impensables, igual que ahora, ¿no es así, querida lectora?” (186). Es obvio que el deíctico "ahora" remite a un tiempo presente que no corresponde al del novelista 
decimonónico, ya que la distancia temporal entre los sucesos narrados y la de su presente no es tan grande como para que resulte efectiva la comparación. Desde el inicio de la novela el narrador advierte esta proclividad a adoptar un estilo y tono arcaizante:

De haber nacido en otros tiempos tal vez este sería el momento de la invocación. Diría "Canta musa celeste, canta, inspira mi atribulado corazón" [...] Lector suave y carísimo, discreto y prudente, sé tolerante con estas pobres musas que han osado sentarse en mi regazo. Pero lástima, ya nadie se acuerda de las musas y algún desconfiado lector estará mostrando escepticismo por el tono con el que he decidido empezar esta novela (11).

De manera que la narración presenta una continua tensión de tonos y estilos de escritura. Cierto que el motivo de la re-creación de la obra perdida del novelista José Turrisa justifica esta simulación en la escritura. Pero este enmascaramiento del escritor del siglo XXI como escritor decimonónico es más que un artificio literario, hace evidente la continuidad y la ruptura de la nueva manera de novelar la historia, la "posmoderna", respecto de la de sus antecesores. Este diálogo y enfrentamiento con la tradición de la novela histórica se explicita en una de las intervenciones autoriales:

¿Nos encontramos ante una novela histórica? No estaría tan seguro. Dudo que el adjetivo "histórico" logre superar al sustantivo "novela" ¿Cómo escribir una novela basada en hechos reales del siglo XIX sin rendirse a las convenciones de la novela decimonónica? ¿Cómo resolver el conflicto, si acaso existe, entre ficción e historia? (79).

En otra de esas reflexiones, que inicia el capítulo titulado "El novelista", el autor especifica cuál es la preocupación determinante de la escritura de su álter ego, el novelista decimonónico:

Es hora de que nos concentremos en el carácter, vida y pensamiento del novelista, que se ha movido como un fantasma a través de esta historia peregrina y cuya pregunta constante, mientras concibe y escribe su novela, ha sido: ¿cómo procesar tantos detalles y tantas anécdotas dentro del enorme alambique de la realidad para que el producto de la destilación posea la intensidad, la transparencia, carácter y sabor de la vida? (261; cursivas mías). 
El novelista decimonónico procura la exactitud histórica, aun cuando esta se presente bajo el tamiz de la ficción. Para él, la verosimilitud está estrechamente vinculada con un mayor apego a la "verdad histórica”. Por su parte, el novelista del siglo XxI encuentra que las fronteras entre ficción y realidad histórica son más difusas que en la percepción del escritor decimonónico; de ahí que cuestione la inclusión de su obra en el género novela histórica, en tanto que, desde su perspectiva, lo "histórico" difícilmente logra superar a la ficción. ${ }^{2}$ La consigna aristotélica de que "la historia se encarga de narrar los sucesos tal y como sucedieron mientras que la literatura los cuenta como pudieron o debieron haber sido" (79), que el autor implícito pone en el recuerdo de su novelista, corrobora la idea de que, más allá de que corresponda o no a la realidad, la literatura ofrece una interpretación de los hechos históricos, si no verdadera, sí válida.

Las convenciones de la novela decimonónica a las que el autor implícito alude proliferan en la escritura, pero expuestas de manera evidente, simuladas de modo deliberado, por lo que denuncian esa intención de utilizarlas para la creación de una obra que, como el mismo autor sugiere en el "Epílogo", se acerque a la definición de pastiche o palimpsesto: "Al novelista le quemaron su obra y yo me arrogué la temeraria responsabilidad de reconstruirla más de ciento cincuenta años después. Pero ¡lástima!, ninguna novela, de ningún autor, puede convertirse en mera reproducción de otra y ni siquiera un pastiche o un palimpsesto podrían hacer justicia al original" (363).

El estilo decimonónico con que el autor-narrador enmascara su relato le confiere la apariencia de una obra "pastiche", ya que, como el mismo autor implícito sugiere, la labor que se ha impuesto es la de escribir una novela del siglo XIX que sea, a la vez, una novela de su tiempo. Peninsula, peninsula es obra pastiche en tanto que supone la creación de un texto a partir de la imitación, explícita, de un estilo acorde con los cánones del romanticismo decimonónico de José Turri-

\footnotetext{
${ }^{2}$ Esa dubitación del autor al definir su obra como novela histórica puede deberse a que el concepto de "verdad", asociado al discurso histórico, se ha vuelto relativo. Para el novelista del siglo XIX, lo "histórico" se imponía a la ficción, es decir que el artificio literario o novelesco debía estar supeditado a una intención de exactitud histórica; sin embargo, para el novelista contemporáneo, el calificativo "histórico", como ya no tiene necesariamente la cualidad de "verdad", ha perdido el efecto de veracidad que antes imprimía al sustantivo "novela".
} 
sa. Imitación de estilo que involucra la adecuación a un género, el de novela histórica, y, en cierto sentido, su transgresión con respecto a la tradición decimonónica.

La mayoría de los sucesos que forman la historia de Turrisa corresponden a la biografía de Sierra O'Reilly; sin embargo, la historia de Turrisa se aparta de la historia de vida de Sierra O'Reilly en ciertos aspectos como el amoroso. ${ }^{3}$ Aun cuando su historia en la novela tenga un fundamento histórico concreto, José Turrisa no deja de ser el autor ficticio de una obra también imaginada. Son varios los historiadores que refieren la pérdida de una enorme cantidad de documentos valiosos sobre la historia de la península de Yucatán durante la quema de la biblioteca de Sierra O'Reilly en la ciudad de Campeche, y se especula también que entre las obras destruidas se encontraba el manuscrito de una extensa novela inédita del autor, que versaba sobre la historia de la piratería en la península, y que llevaría por título Los filibusteros del siglo diecinueve. Al parecer, la novela Un año en el hospital de San Lázaro, publicada por vez primera en El Registro Yucateco en 1845, correspondería a un episodio de esa novela más extensa que, se supone, el escritor no logró concluir. Así lo confirma la nota del autor con la cual finaliza la publicación de la novela en El Registro Yucateco: "Hace algún tiempo que estoy ocupado

${ }^{3}$ Llama la atención que sea precisamente la historia de amor entre Lorenza y Turrisa el elemento más "novelesco" (entendido el término como ficticio) de la historia del personaje, si se tiene en cuenta que en la tradición literaria decimonónica, la de las novelas de Sierra O'Reilly, como La hija del judio, solía ser precisamente el tema amoroso en el que recaía el elemento ficcional. En la vida real, Sierra O'Reilly sí contrajo matrimonio con Conchita, la hija del gobernador Méndez, circunstancia a la que se atribuye, en gran medida, algunas de las decisiones más polémicas u "oscuras" en la vida del escritor yucateco, como lo es su apoyo, posterior a los años de la guerra de castas, a la trata de indios mayas iniciada por su suegro, hecho que contrasta radicalmente con la imagen del intelectual interesado y defensor de la cultura indígena, que se desprende de varios de sus escritos sobre la civilización maya publicados en sus periódicos literarios, anteriores, claro está, a la guerra de castas. Cierto que tampoco se puede obviar el hecho indiscutible de que una guerra como la sufrida por Sierra O'Reilly y sus coetáneos pudo influir de manera tan drástica en el espíritu de un arduo defensor de la civilización maya, a la que idealizó como "pasado glorioso". La imagen de José Turrisa en la novela, menos comprometida con la figura de Méndez, muestra el lado más amable, el menos polémico de Sierra O’Reilly, el del novelista romántico. Al delegar a otro personaje, a Justo Sierra O'Reilly, el político, la responsabilidad de algunas acciones y decisiones controversiales del personaje real, Lara Zavala consigue convertir a José Turrisa en héroe novelesco, al estilo decimonónico. 
en bosquejar una extensa novela que, bajo el título de Los filibusteros del siglo diecinueve, pienso publicar en mejor ocasión. Un año en el Hospital de San Lázaro no es más que un episodio de esa novela y, por lo mismo, es aquí donde debe terminar" (Sierra O’Reilly 1849: 479).

De manera que Lara Zavala elabora el motivo de la novela desaparecida de Turrisa sobre la historia de Yucatán en el siglo XIX, a partir del hecho real de la pérdida en el incendio de documentos valiosos que hubiesen servido para construir esa historia y del manuscrito nunca hallado de una novela inédita del autor. Cuando en el "Epílogo" el autor implícito se lamenta de no haber podido "reconstruir" la novela de José Turrisa, de no haberle, al menos, hecho "justicia al original" (363), hay que leer la expresión de lamento con un tono irónico, ya que el mismo autor, en sus reflexiones metatextuales, había declarado su preocupación por "no ceder a los convencionalismos de la novela decimonónica" (363). Más que el reconocimiento de la imposibilidad de reconstruir la novela decimonónica, las mediaciones autoriales expresan la intención de no asimilar el estilo decimonónico al grado de que no pueda advertirse el artificio literario del novelista contemporáneo. Esas irrupciones forman parte del antídoto contra los convencionalismos de la novela decimonónica, ya que aluden a las circunstancias creativas del autor contemporáneo, personaje de ficción que desea recrear la supuesta novela perdida del siglo XIX.

Además, el narrador nunca suelta del todo la voz a su álter ego decimonónico, José Turrisa. La presencia del escritor "actual” es constante en la narración, se asoma a veces como sombra, y su voz, su pensamiento, nunca deja de ser el eco tras la voz y el pensamiento de Turrisa. Se puede hablar, entonces, de la simultaneidad de dos voces en el relato, e incluso de dos perspectivas, pero, en realidad, no puede afirmarse que hay dos narradores, sino uno solo que parece tener la capacidad de narrar desde dos espacios y dos tiempos a la vez. Acaso cabría definir a este narrador de la manera como se define el propio escritor en sus consideraciones metatextuales: "Escribo en diferentes lugares, en diferentes medios, con diferentes medios. Soy un escritor ubicuo" (111; cursivas mías). El autor alude otras veces a esta capacidad para estar en distintos lugares a la vez en relación con el momento de escritura: “¿dónde habré escrito este capítulo? Y me percato de que me encuentro en varios lugares simultáneamente" (185); o bien hace referencia a su capacidad para "transportarse" de un espacio a otro por medio de la evocación: 
Miro hacia un cementerio con tumbas y cruces de piedra gris, muchas de ellas celtas [...] Hoy veo desde mi ventana el reloj negro con manecillas doradas de la iglesia de Saint Andrews [...] El reloj me hace consciente de que al momento de escribir esta página me encuentro en Cambridge, Inglaterra [...] Y esto me lleva a transportarme al cementerio del pueblo de mi padre (149; cursivas mías).

No es gratuita esta insistencia acerca de la comunión de espacios y tiempos, vinculada al proceso de creación de la novela, si se considera como un guiño de lo que sucede a lo largo del texto con la voz narrativa, que parece pertenecer a un narrador también ubicuo, que consigue esta sensación de ubicuidad por medio del enmascaramiento. Es decir, el narrador contemporáneo, novelista del siglo XxI, está en continuo movimiento entre dos espacios y tiempos a la vez; se apropia de la memoria, la mirada y la voz narrativa del novelista decimonónico, simula ser él y nos describe el Yucatán del siglo xix, pero sin despojarse del todo de su voz y de su mirada de novelista posmoderno.

La península de Yucatán se presenta a través de dos memorias: la de José Turrisa, reconstruida a partir de los testimonios históricos y literarios de Sierra O’Reilly, en su mayoría, y la memoria de un autor implícito, identificable con Hernán Lara Zavala, labrada por la propia historia familiar en el pueblo de Hopelchén, que puede rastrearse en otros textos literarios, más cercanos a lo histórico, como su crónica Viaje al corazón de la península (1998).

Para el novelista del siglo xxI, la creación de la novela implica adentrarse y apropiarse de la memoria del "otro", de su manera de pensar "como ciudadano del siglo xIx" (Lara 2008: 262), pero, sobre todo, como novelista, como creador decimonónico: "Imagino al novelista imaginando el ruido que producen las botas del todavía capitán Cirilo Baqueiro mientras camina en tanto la plumilla del escritor corre sobre el papel” (67). Esta adopción de la memoria histórica y de la imaginación creativa del escritor del siglo xix, conlleva, como es obvio, una adaptación en la que se filtra la memoria y la imaginación creativa del novelista contemporáneo. El estilo decimonónico en la escritura se presiente, pues, voluntariamente impostado. El afán en los detalles costumbristas, por ejemplo, en la descripción minuciosa de la vestimenta, del decorado y de las danzas durante el llamado "Baile Verde", imprime al relato un tono didáctico que se justifica, sobre todo, por la intención 
de mirar los hechos tras los "quevedos de José Turrisa". Carlos Fuentes, en su artículo "El Yucatán de Lara Zavala", opina que "el tránsito de Lara Zavala de su irónica actualidad de narrador a la materia narrada, le permite presentar esta, la Guerra de Castas en Yucatán, con una variedad de ritmos y temas que no solo la salvan de cualquier sospecha de didactismo, sino que enriquecen lo que ya sabíamos con el tesoro de lo que podemos imaginar" (Fuentes 2008; cursivas mías). Si se "sospecha de didactismo" en la novela es porque realmente hay un tono didáctico en ella, pero este es intencional, ya que forma parte del juego literario, de la simulación de estilo que el texto pretende.

El prurito de "exactitud histórica" es otro de los convencionalismos de la novela decimonónica que el narrador expone como parte de la "imitación" del estilo de José Turrisa. La tendencia a adecuar la narración a las convenciones del estilo decimonónico es abiertamente expresada en diversas ocasiones en el texto. Por ejemplo, cuando el narrador se dispone a describir a Lorenza, declara:

El novelista no quería dejar de lado su belleza para presentarla a los lectores, y aunque podía recurrir a modelos de otras novelas se decidió por lo que él llamaba "la exactitud histórica" y así determinó que Lorenza se tendría que apegar a como era cuando él la vio en el baile: rubia, cabello ligeramente rizado, blanca, alta; grandes ojos azules dominaban su rostro y poseía una mirada serena, lánguida, aterciopelada así como una bella y gentil sonrisa (Lara 2008: 15).

Además, hay que tener en cuenta que la referencia en el texto a Borges no es, en absoluto, gratuita, la novela abre con un epígrafe del escritor argentino y cierra, en el epílogo, con la misma cita, aunque parafraseada: "Cuatro son las historias. Durante el tiempo que nos quede seguiremos narrándolas, transformándolas". La idea de la reescritura que apunta la cita de Borges es esencial para entender la propuesta estética de la novela de Lara Zavala. El autor de Peninsula, peninsula se propone la reescritura de una obra que sea a la vez la "misma" y "otra", no importa si lo narrado y la manera como se narre sean "idénticas", el horizonte histórico y cultural de la obra será distinto y esto la hace también diferente. La reiteración, como en vocativo, del término "Península", posee un acento dramático que sugiere el acendrado sentimiento patriótico acorde con el suceso narrado, aunque también se puede referir 
a la dualidad de espacios que entroncan en la novela, dos penínsulas que, siendo la misma, son distintas en relación a la mirada de quien las describe; la península de José Turrisa es la misma y a la vez distinta de la que reconstruye el novelista contemporáneo.

Para adentrarse en el horizonte histórico-cultural de José Turrisa, el autor recurre a diversos documentos históricos y literarios de la época, muchos de los cuales pueden identificarse como obra de Justo Sierra O'Reilly. Sobra decir que José Turrisa era el seudónimo de don Justo Sierra O'Reilly, anagrama de su nombre, como también lo fue el de Tomás Ysurre, apellidos ambos de origen vasco, populares en la península. Como José Turrisa, Sierra O’Reilly firmó algunas obras literarias primordiales, como sus "leyendas" que aparecieron en El Museo Yucateco (1841-1842), simientes de sus novelas históricas: Un año en el hospital de San Lázaro y La hija del judio.

En el capítulo titulado "El novelista", cuando el autor implícito manifiesta su intención de adentrarse en el pensamiento de José Turrisa, "como ciudadano del siglo XIX", se percibe de manera más definitiva el trabajo de archivo, fundamentado, en especial, en la obra de Justo Sierra O'Reilly. Las opiniones sobre el obispo fray Diego de Landa que el autor expone en este capítulo se basan, como ahí mismo refiere, en los diversos artículos que publicara Justo Sierra O'Reilly en sus distintos periódicos, por ejemplo, en El Fénix (1848-1851), sobre las causas sociales e históricas que desembocaron en la guerra de castas.

Es notable el apoyo bibliográfico al que recurre el autor para la recreación de la novela perdida de Turrisa. Por ejemplo, en el pasaje donde sucede la boda de Lorenza con Turrisa, "Bajo la lluvia", la información sobre la catedral de Mérida que Lorenza recuerda es entresacada de un artículo de Sierra O'Reilly publicado en su revista El Registro Yucateco en 1845, y que apareció acompańado de una hermosa litografía de la catedral. También la información sobre los obispos de Yucatán que consigna en el último capítulo dedicado a la figura del padre Celestino Onésimo tiene como fuente otros textos de Sierra O'Reilly, su "Galería Biográfica de los señores Obispos de Yucatán” que publicó en los cuatro tomos de El Registro Yucateco; en la novela se hace referencia en particular a la biografía de fray Diego de Landa.

La mayoría de las fuentes documentales, las que pertenecen a Sierra O'Reilly, se consignan de manera explícita en el texto. En el caso de la configuración del padre Onésimo, el narrador llama la atención sobre 
la distancia que existe entre este personaje con su referente en la realidad, don José María Guerra, quien fuera obispo de Yucatán en el tiempo en el que sucedieron los hechos históricos narrados:

me gustaría servirme ahora del retrato, no de quien fue el verdadero obispo durante el periodo que nos ocupa, monseñor José María Guerra, hombre sensato, mesurado y muy humano, sino de quien nos hemos servido para recrear esta historia y que bautizamos con el nombre de monseñor Celestino Onésimo Arrigunaga. Observémoslo, no a través de su retrato, sino de nuestra narración (337).

La aclaración del carácter ficcional de este personaje y la alusión al personaje histórico real, el obispo José María, forma parte del artificio del que se vale el autor para representar el conflicto entre ficción y realidad que, como en otro momento declara, es una de sus preocupaciones al "rescribir" la novela histórica perdida.

Puede afirmarse que Lara Zavala toma como fuentes históricas para la ficción novelesca, de manera primordial, dos acervos bibliográficos: la obra de Sierra O'Reilly y su propia obra. Del acervo de Sierra O’Reilly, retoma algunos documentos históricos y literarios como sus Diarios de viaje a Estados Unidos, sus artículos sobre la guerra de castas aparecidos en El Fénix, sus biografías sobre personajes ilustres de la sociedad yucateca, sus diversos artículos sobre la cultura maya que se encuentran en sus dos revistas literarias, además de los que antes he anotado. En cuanto a la relación intratextual, esta se establece, de forma particular, con su crónica Viaje al corazón de la península (1998), en la que el autor entrelaza el relato de su recorrido por la península con la referencia a pasajes y personajes de su pasado familiar, en el pueblo de Hopelchén, y con la serie de relatos que publicó bajo el título de De Zitilchén (1994).

Diarios de un "viaje al corazón de la Península", de Hernán lara Zavala a Miss BelL

La historia de Hopelchén, pueblo de la región de los chenes ("pozos", en lengua maya), se inserta en la novela como una microhistoria que refleja, en mise en abyme, la historia principal: la guerra de castas foca- 
lizada en sus protagonistas; hombres "blancos", mayas, o aventureros entrañables como Fritzpatrick y Miss Bell. En la historia de Hopelchén, registrada por la mirada curiosa y asombrada de Miss Bell en sus diarios, se aprecia, en síntesis, las costumbres de la sociedad yucateca, se da cuenta de las relaciones injustas, despóticas, que establecían los "blancos" con los "indios", y que dieron pábulo al rencor que explotó en la cruenta guerra. Algunos datos significativos consignados en los diarios de Miss Bell, que sirven para exponer el abuso de poder de las familias "blancas" hacia los mayas, se pueden rastrear en la crónica del viaje a Yucatán de Hernán Lara Zavala, antes mencionada. Baste como ejemplo una anécdota referida en la crónica, sobre un personaje de la historia familiar del autor:

De todos estos personajes el más pintoresco fue precisamente el tío Emilio Lara Milín que empezó como catador de la hacienda y que, en su calidad de "jure", ejerció el derecho de pernada sobre las indígenas del lugar. Durante su juventud el tío Milín se dedicó a ejercer el "derecho de pernada" de modo tan cínico, que cuenta la leyenda que llevaba una libretita en la que consignaba los nombre de todas las mujeres que pasaban por sus brazos (Lara 1998: 91).

Esa anécdota forma parte de los diarios de Miss Bell, aunque se la presenta con mayor detalle y se cambian algunos datos como el nombre del personaje:

El otro día me enteré que don Francisco, en su calidad de "jure", ejerce el "derecho de prioridad" sobre las mujeres núbiles de allí y que ninguna puede esquivar sus caprichos y escarceos eróticos que, según él afirma, registra minuciosamente en una libretita en la que anota nombre, fecha y circunstancia en que las poseyó (Lara 2008: 209).

En la novela, en particular en los capítulos dedicados a Miss Bell, abundan datos, nombres y circunstancias cuyos referentes históricos pueden rastrearse en la crónica de viaje del autor. Pero la relación de los diarios de Miss Bell con la crónica de Hernán Lara Zavala, también se establece en un sentido genérico, es decir, los diarios de Miss Bell se acercan, por su estilo y estructura, a las crónicas de viajes, sobre todo, aquellas mediante las que muchos viajeros extranjeros del siglo XIX mostraron al mundo la belleza y riqueza cultural de la península de Yucatán, 
y de otras regiones de México. ${ }^{4}$ Hay que recordar la inclinación de los viajeros extranjeros y nacionales por referir mediante crónicas la belleza natural y la riqueza cultural de la península, entre los más famosos se encuentra Mr. John Lloyd Stephens, quien escribió Incidents of travel in Yucatán, obra en la que también refirió la situación social de los indios mayas, y que tradujo al español por primera vez Justo Sierra O’Reilly, para los lectores de El Museo Yucateco. ${ }^{5}$

Aunque los escritos de Miss Bell se definan como diarios, escritura de tono más íntimo, este rasgo no contraviene que puedan leerse también como una crónica de viajes, al estilo decimonónico. Como afirma Belem Clark de Lara, la crónica se transformó de manera paulatina, de modo que en las primeras décadas del siglo XIX aún se limitaba a su función de archivo o registro histórico (327). Si bien, en sus comienzos, la crónica tenía como fin primordial el registro del acontecer histórico, y era un género por lo común cultivado por historiadores y periodistas, a partir de la segunda mitad del siglo, en la pluma de literatos adquirió rasgos que la acercaron mucho más al ámbito de la literatura, sobre todo de sesgo romántico y costumbrista. Así que el tono personal, íntimo, de los diarios de la señorita Bell, no fue un rasgo indiferente al estilo de las crónicas decimonónicas, pues en ellas el registro de lo visto y vivido en los viajes o en el acontecer cotidiano involucraba la expresión de los sentimientos e impresiones del autor.

Por lo común, esos cronistas decimonónicos urdían la relación de sus viajes con las de sus sensaciones y hasta de sus "cuitas interiores", como escribiera Manuel Payno al referirse precisamente a una de sus crónicas de viaje. ${ }^{6}$ Por las mismas fechas de las crónicas de Payno, Sierra

\footnotetext{
${ }^{4}$ La crónica de viajes fue un género muy cultivado en el periodo decimonónico, ya que servía bien a los propósitos nacionalistas de forjar la identidad mediante la valoración de la riqueza nacional, deseo que concordaba con la propuesta de la corriente estética del romanticismo que postulaba la exploración del "espíritu del pueblo" en la literatura.

${ }^{5}$ La traducción de esta obra de Lloyd Stephens, Sierra O’Reilly la titula Viaje a Yucatán a fines de 1841 y principios de 1842. Consideraciones sobre los usos, costumbres y vida social de éste [sic] pueblo y examen y descripción de las vastas ruinas de ciudades americanas que en él existen.

${ }^{6}$ De hecho, en 1843, Manuel Payno definió los escritos de este género como crónicas de "viajes sentimentales", al titular a una de sus colaboraciones en El Museo Mexicano: "Viaje sentimental a San Ángel". El mismo autor, como introducción a su crónica, subraya ese tono intimista que se mezcla con el registro de su itinerario de viaje: "amo
} 
O'Reilly publica las suyas en las que también se aprecia este matiz intimista y literario, primero en El Museo Yucateco y más tarde en El Registro Yucateco, ${ }^{7}$ periódico este último en el que, curiosamente, la señorita Bell se informa sobre la historia de Yucatán y de la cultura maya. En particular, refiere su lectura de un artículo sobre Jacinto Can Ek de José Turrisa, que en efecto, publicó Justo Sierra en esa revista:

28 de marzo, 1848. Leyendo un pequeño periódico llamado El Registro Yucateco, hoy me enteré de una sublevación indígena que ocurrió en 1761 en el pueblo de Quisteil, que me ha recordado los orígenes de esta guerra. El artículo está firmado por un tal José Turrisa y cuenta la triste historia de Jacinto Can Ek (Lara 2008: 208).

La definición de crónica va bien a los diarios de Miss Bell si se considera que, como apunta Álvaro Matute, el cronista, al ser el relator fiel de lo que mira, de lo que acontece en su entorno y es testigo, se convierte en una especie de "microhistoriador", pero su registro no se determina por los "cánones" de un historiador, en ellos intervienen rasgos que acusan la libertad del escritor, como la especial percepción de los hechos, la agudeza, su fuerza evocadora (717). Sobra aclarar el papel de "microhistoriadora" que la señorita Bell juega en la novela, ya que en sus textos no solo da testimonio del acontecer diario de su vida en Hopelchén, sino que, en su afán de "entender" ese acontecer, ese presente al que intenta adaptarse, emprende una revisión del pasado de Yucatán.

En algunos fragmentos de su diario, la institutriz inglesa registra vivencias en las que el mito y la leyenda se empalman con la realidad, como el pasaje del Huay Chivo y del Huay Chup, y páginas adelante, consigna datos sobre la historia de la civilización maya, de su cosmovisión, que delatan esa intención de enlazar el pasado con el presente, más bien de tratar de entenderlo. Pero, sobre todo, los fragmentos de

tanto a mis desconocidos lectores, por la indulgencia con que toleran mis escritos, estoy tan acostumbrado a darles cuenta de mis aventuras, de mis sensaciones, y hasta de mis cuitas interiores, que me es imposible contarles en tono sentimental, a la manera de mi buen Sterne, mi viaje a San Ángel” (386).

${ }^{7}$ Tampoco hay que olvidar que el Diario de nuestro viaje a los Estados Unidos de Sierra O'Reilly es un texto que fusiona estos dos géneros, es decir el diario y la crónica, como sucede en los escritos de Miss Bell. 
los diarios atestiguan los sutiles y paulatinos cambios en la vida de la sociedad "chenera" ante la amenaza creciente de la llegada al pueblo de los rebeldes mayas, aunada al registro de información sobre la historia de la península, en particular sobre la época colonial, que intentan explicar las condiciones sociales del presente. Por tal motivo, pueden leerse los capítulos de la señorita Bell como una "microhistoria" que, como he mencionado, es reflejo y síntesis de la historia de la guerra de castas que se desarrolla a lo largo de la novela.

Y también es evidente que el estilo de su escritura no es el de un texto histórico, sino que, como corresponde al carácter híbrido del género crónica, en la relación de Miss Bell se advierte una "especial percepción de los hechos, la agudeza, su fuerza evocadora". Y la fuerza evocadora se la da, en gran medida, un estilo que, por momentos, recuerda al de algunas estampas o cuadros costumbristas de la época. No era extraño, además, que los autores decimonónicos insertaran en sus crónicas escenas o cuadros costumbristas. De nuevo, las crónicas de Sierra O'Reilly de la época son ejemplo de lo dicho; baste mencionar una de ellas: "Las diligencias y la feria de Izamal", relación lúdica de algunos de sus viajes en diligencia en territorio yucateco, y de su visita reciente a la feria del poblado de Izamal, Yucatán, en la que inserta una animada pintura de las costumbres de la sociedad en un día de feria:

Allí los paseos, bailes, comilonas, juegos, compras y ventas [...] por todas partes se reúnen en Izamal las gentes, los frutos, los productos y artefactos de los distintos pueblos del Estado; suben los romeros y devotos que van a visitar el Templo y el camarín de la Virgen. Luego bajan los espectadores a la plaza chica en que se hace la feria de los caballos, acémilas y demás piezas de carga; luego recorríamos todos los almacenes de ropa, quincallería y abarrotes [...] De la una a las tres de la tarde, había un baile, y el resto de ella se concluía en la mesa y en los paseos sobre los cerros (Sierra O'Reilly 1842: 17).

Algunos pasajes de los diarios de Miss Bell tienen el estilo de un cuadro de costumbres, descripciones de los lugares que visita en las que mezcla referencias a los usos y costumbres de sus pobladores. Uno de los fragmentos que mejor representa esta tendencia a un estilo cercano al costumbrismo literario del siglo xix es precisamente el pasaje que abre la escritura de los diarios. En ese primer fragmento, fechado 15 de febre- 
ro, 1847, la señorita Bell intercala en la relación de su llegada al puerto, una descripción de matiz poético, a manera de un cuadro o boceto, de su primera imagen de la ciudad de Campeche. La mirada asombrada de Miss Bell hacia Campeche se sitúa, en principio, desde la cubierta del barco en el que arriba; es notable la alusión a matices o tonalidades de color en la descripción de la imagen, rasgo propio del estilo de las "pinturas animadas" de la literatura costumbrista:

Después de tan prolongado viaje nuestro barco entró por la mañana en la amplia bahía de Campeche con el sol en todo su esplendor iluminando un mar tranquilo, sedoso y reluciente [...] Desde la cubierta pude contemplar la ciudad con sus impresionantes murallas, torres, baluartes que me cautivaron de inmediato [...] Alrededor de la ciudad todo es verde y sobre la playa vi por primera vez las bellas palmeras meciéndose al vaivén del viento que me trajeron a la mente las exóticas tierras que había conocido solo a través de novelas. Unas breves y verdes colinas se levantaban en el horizonte (Lara 2008: 44; cursivas mías).

La vista de la ciudad se extiende a distintos puntos cuando Miss Bell describe su recorrido y detalla algunos usos y costumbres de los campechanos. Su mirada se centra en detallar lo que para ella resulta "más exótico", es decir, la fisonomía, la vestimenta, el carácter de los indios:

Por lo poco que pude observar, Campeche es una ciudad pequeńa pero muy próspera, con mucho comercio, marinos de todas partes del mundo y una enorme iglesia desde la que se domina la bahía [...] Para mi sorpresa abundan los indios, los cuales se reconocen fácilmente: visten de manta blanca, la mayor parte con pantalón corto bajo la rodilla, sombrero de palma y buena parte anda descalza o cuando mucho con alpargatas. Tienen un rostro triangular, anguloso, ojos rasgados, nariz prominente [...]; son bajos de estatura, los hombres delgados y las mujeres entradas en carnes, pues para ellos lo rollizo es síntoma de bonanza [...]; son silenciosos, tranquilos y se comportan de manera sumisa (44).

En distintas partes del diario de la señorita Bell se presentan descripciones con detalles costumbristas de la región de los Chenes. Por ejemplo, las abundantes alusiones a la gastronomía de la región, en las que se advierte la tendencia, común en la escritura de los cronistas extranjeros, a descri- 
bir lo "extraño", lo "otro", con referentes culturales propios o conocidos. Esto sucede con la descripción del marañón: "Es un fruto más pequeño que una pera de tonos brillantes en verde, rojo, naranja y amarillo y cuya semilla crece en la parte inferior como el pico de un tucán" (50).

Pero esa descripción de Campeche, una de las más poéticas del diario de la institutriz, recuerda, en particular, un cuadro de costumbres del escritor decimonónico Isidro Rafael Gondra, otra pintura poética de Campeche también visto desde el mar, que, a semejanza de la de Miss Bell, se amplía a distintos aspectos y planos de la ciudad, y ofrece detalles sobre su arquitectura, su riqueza natural, gastronómica, así como de algunos usos y costumbres de los campechanos. El texto, titulado precisamente "Campeche visto desde el mar", se publicó en la revista $E l$ Museo Yucateco. Cito, por lo menos, un fragmento que da cuenta de la imagen, casi "pictórica", de ese Campeche que visualizó Rafael Gondra, como Miss Bell, desde el barco que lo trajo a esas tierras:

Descuellan sobre sus sólidas murallas la gentil torre de la iglesia parroquial y la menos elevada de San Juan de Dios [...] Los edificios en hermoso desorden alternan con solares o pintorescas huertas, sobre cuyos cercados de corta elevación extienden sus anchurosas hojas el plátano y la guanábana, el arramilletado naranjo y el delicioso saramuyo [...] Tan bella perspectiva se mira terminada por un mar de plata, donde el sol hace brillar sus rayos de oro entre el variado matiz de los más bellos colores, al tiempo de esconderse en el ocaso, mientras que por otro lado tersas sus aguas cual cristal transparente, remedan a un espejo en que se ven pintados a la vez el claro oscuro del fondo y el azulado espacio, donde el astro de la noche reverbera sus luces débiles hasta que apagados los fulgores del crepúsculo de la tarde, se presentan como duplicadas de las olas al cielo (70).

$\mathrm{Al}$ establecer la correspondencia entre esa descripción de Miss Bell y el texto "Campeche visto desde el mar" no afirmo que este último sea su intertexto específico. Solo pretendo mostrar cómo, por su estilo de escritura, los capítulos que corresponden a los diarios de la señorita Bell forman parte del diálogo que la novela establece con la tradición literaria decimonónica, en este caso, con el estilo de los cuadros de costumbres de la literatura de la época.

Cierto es que las relaciones intertextuales que establece esta novela no se restringen al ámbito de la literatura del siglo xIx. Es evidente su 
vínculo con la literatura inglesa del siglo xx; en específico con la obra de Faulkner, Absalom, Absalom, e incluso con el Ulises, de Joyce ${ }^{8}$ y, por supuesto, el de Homero. Pero entre la riqueza intertextual que sugiere la lectura de Peninsula, peninsula, y que valdría la pena desentrañar a profundidad, me avoqué en este trabajo a mostrar, sin agotarlos, solo algunos de sus posibles nexos con la literatura del siglo xIx, porque una de sus pretensiones manifiestas es la de señalar la "ruptura" de la novela histórica contemporánea con su tradición iniciada en esa época; subrayar sus diferencias, al mostrar, paradójicamente, los convencionalismos del estilo decimonónico sin caer en ellos.

\section{BiBLIOHEMEROGRAFÍA}

Bobadilla Encinas, Gerardo Francisco. La poética de la novela histórica mexicana del siglo XIX: la bistoria y cultura como testimonio mítico. Tesis de Doctorado. El Colegio de México, Centro de Estudios Lingüísticos y Literarios, febrero de 2002.

Clark de Lara, Belem. "La crónica en el siglo XIX". La república de las letras. Asomos a la cultura escrita del México decimonónico, vol. I. México: Universidad Nacional Autónoma de México, 2005: 325-353.

Fuentes, Carlos. "El Yucatán de Lara Zavala" [2008], en Arte Literal. Escritura venezolana boy <http://www.arteliteral.com/al/index.php/poesia/135el-yucatan-de-lara-zavala.html>.

Genette, Gerard. "Pastiche ficticio", en Palimpsestos. Trad. Celia Fernández. Madrid: Taurus, 1989: 118-125.

Gondra, Isidro RAFAel. "Campeche visto desde el mar", en El Museo Yucateco,1841-1842. Campeche, II (1841): 15-19.

Hartog, François. Regímenes de historicidad. Presentismo y experiencias del tiempo. Trads. Norma Durán y Pablo Avilés. México: Universidad Iberoamericana, 2007.

Lara Zavala, Hernán. Península, península. México: Alfaguara, 2008.

Lara Zavala, Hernán. Viaje al corazón de la península. México: Consejo Nacional para la Cultura y las Artes, 1998.

Lara Zavala, Hernán. De Zitilchén. México: Consejo Nacional para la Cultura y las Artes, 1994.

${ }^{8}$ La relación con la obra de Joyce se establece también a partir del motivo de la reescritura. Joyce emprende, con el Ulises, la adaptación de la trama homérica en un contexto contemporáneo. 
Matute, Álvaro. “Crónica: historia o literatura”, en Historia Mexicana. XLVI, 4 (1997): 717-718.

Menton, Seymour. La nueva novela histórica de la América Latina, 1979-1992. México: Fondo de Cultura Económica, 1993.

Sierra O’Reilly, Justo (ed.), El Museo Yucateco. Campeche, I-II (1841-1842).

Sierra O’Reilly, Justo (ed.), El Registro Yucateco. Campeche/ Mérida, I-IV (1845-1849).

Sierra O’Reilly, Justo. “La Catedral de Mérida”, en El Registro Yucateco, Mérida, I (1845): 131-142.

Sierra O’Reilly, Justo. “Galería Biográfica de los señores Obispos de Yucatán, Dr. D. Fr. Diego de Landa”. El Registro Yucateco, Mérida, I (1845): $72-80$.

Sierra O’Reilly, Justo. Diario de nuestro viaje a los Estados Unidos. México: Antigua Librería Robredo de José Porrúa e hijos, 1938.

Payno, Manuel, "Viaje sentimental a San Ángel", en El Museo Mexicano, II (1843): 385-389.

Sol Tlachi, Manuel, "La hija del judío, de Justo Sierra O’Reilly: historia de un texto”, en Nueva Revista de Filología Hispánica. El Colegio de México, 55, 1 (2007): 153-163. 